\title{
Mayores requerimientos de levotiroxina en embarazadas con hipotiroidismo
}

\section{Objetivo}

Determinar el tiempo preciso y patrón de aumento en los requerimientos de levotiroxina durante el embarazo en pacientes con hipotiroidismo.

\section{Diseño}

Estudio prospectivo, observacional.

\section{Lugar}

Consultorios externos del Bringham and Women's hospital, Boston, EE.UU.

\section{Pacientes}

Mujeres con diagnóstico de hipotiroidismo que planeaban embarazo. Se incluyeron 20 pacientes que lograron embarazo: 8 pacientes con tiroiditis de Hashimoto, 4 con hipotiroidismo luego de tratamiento por enfermedad de Graves, 2 con nódulo tiroideo benigno y 6 con antecedentes de cáncer de tiroides.

\section{Intervención}

Se evaluaron antes y durante el embarazo. Se evaluó la función tiroidea, HCG y estradiol antes de la concepción, cada 2 semanas durante el primer trimestre y luego mensualmente. Se aumentó la dosis de levotiroxina durante el embarazo para mantener la concentración de TSH en valores preconcepcionales: $\mathrm{TSH}<0.5 \mathrm{uU} / \mathrm{ml}$ en las pacientes con antecedentes de cáncer de tiroides y TSH 0.5 a $5 \mathrm{uU} / \mathrm{ml}$ en las pacientes con patología benigna. Luego del parto se retomó la dosis preconcepcional y se reevaluaron 6 semanas después.

\section{Resultados principales}

Se observaron 20 pacientes embarazadas, 17 a término. Los niveles de TSH aumentaron durante las 10 primeras semanas, por lo cual se incrementaron las dosis de levotiroxina en el $85 \%$ de las pacientes. No se verificó el incremento de T4 libre que ocurre normalmente asociado al pico de HCG. La dosis de levotiroxina se incrementó entre la semana 6 y la 16 con valores meseta posteriores; a las 10 semanas la dosis de levotiroxina aumento $29 \pm 25 \%$ y a las 20 semanas $48 \%$ (ver tabla), sin variaciones posteriores. Las 3 pacientes que se embarazaron mediante método de fertilización asistida tuvieron mayor incremento en la TSH. Las 14 pacientes reevaluadas luego del parto tuvieron valores similares a los preconcepcionales.

\begin{tabular}{l|c|c|c|c|c|c|c}
\multicolumn{1}{c|}{ Variable } & Pre-embarazo & 10 semanas & 20 semanas & 30 semanas & 38 semanas & p (ANOVA) \\
\hline TSH $\mathrm{UU} / \mathrm{ml}(\mathrm{X} \pm \mathrm{SD})$ & $1,0 \pm 1,14$ & $4,2 \pm 3,8$ & $2,3 \pm 3,2$ & $1,3 \pm 1,5$ & $1,0 \pm 0,9$ & 0,002 \\
\hline Indice T4libre $(\mathrm{X} \pm \mathrm{SD})$ & $8,8 \pm 1,2$ & $7,8 \pm 1,8$ & $8,9 \pm 1,5$ & $8,5 \pm 1,7$ & $8,5 \pm 1,8$ & 0,33 \\
\hline Dosis de levotiroxina (\%) & Referencia & $+29 \pm 25 \%$ & $+48 \pm 18 \%$ & $+48 \pm 15 \%$ & $+47 \pm 17 \%$ & $<0,001$ \\
\hline $\mathrm{X}$
\end{tabular}
$\mathrm{X}$ : media

\section{Conclusiones}

Los requerimientos de levotiroxina aumentan tempranamente en el embarazo en pacientes con hipotiroidismo.

Fuente de financiamiento: no referida.

\section{Comentario}

Los autores confirman con este trabajo la necesidad de incrementar las dosis de levotiroxina en pacientes hipotiroideas sustituidas, para mantener los niveles preconcepcionales de TSH, y observan que los requerimientos aumentan desde la quinta semana de embarazo, momento en el que el aporte materno de T4 es importante.

El hipotiroidismo no tratado durante el embarazo se asocia a complicaciones maternas y fetales, con aumento en mortalidad perinatal y anormalidades congénitas. El eje hipotalamo-hipofiso-tiroideo fetal comienza a funcionar al final del primer trimestre, antes de lo cual el cerebro fetal utiliza la T3 formada a partir de la T4 de origen materno. El pasaje transplacentario de tiroxina (T4) particularmente durante el primer trimestre del embarazo es importante para el desarrollo neurológico fetal y el futuro coeficiente de inteligencia. Si bien no existen trabajos de intervención que demuestren beneficios del tratamiento en pacientes embarazadas con hipotiroidismo subclínico, el potencial beneficio justificaría el tratamiento de estas pacientes.

En condiciones normales la tiroides materna incrementa la producción de tiroxina. Esto se debe por una lado a la disminución en los niveles de T4 libre por el aumento en la globulina transportadora de T4 (TGB) inducida por los estrógenos, a la pérdida de T4 por pasaje y degradación placentaria, y a la menor disponibilidad de yoduros por el aumento en su eliminación urinaria. La HCG de origen placentario tiene un efecto tiroestimulante, aumentando la producción de T4 y de ésta forma compensa las pérdidas mencionadas. Pero esto no ocurre cuando la producción hormonal se halla limitada como sucede en zonas con deficiencia de yodo o en pacientes con hipotiroidismo.
Las limitantes del trabajo son el escaso número de pacientes, y la inclusión de pacientes con patología maligna, en las cuales se administra dosis mayores de levotiroxina para mantener la TSH en niveles inferiores a lo normal. De igual forma, en éstas pacientes también se observó aumento en los requerimientos.

Los autores proponen aumentar la dosis de levotiroxina, dos dosis extra semanales al momento de la confirmación del embarazo, para así evitar la hipotiroxinemia durante el primer trimestre del embarazo. Considerando que son escasos los riesgos de dicha medida y grandes los potenciales beneficios del óptimo control, es una medida adecuada el incremento de la dosis al momento de la confirmación del embarazo. Luego se debe monitorear los niveles de TSH cada 6 a 8 semanas para regular la dosis según necesidad

\section{Conclusiones del comentador:}

$\mathrm{Si}$ bien no existen trabajos de intervención en mujeres embarazadas hipotiroideas sustituidas que muestren beneficios de mantener niveles de TSH dentro del rango normal del método, tomando en cuenta los riesgos del hipotiroidismo para el desarrollo fetal, el buen control tiroideo es muy importante. Tomando en cuenta que los requerimientos de levotiroxina aumentan tempranamente, es una buena medida el incremento de $25-30 \%$ de la dosis al momento de la confirmación del embarazo para así evitar el potencial control subóptimo durante el primer trimestre y sus posibles consecuencias, más aún tomando en cuenta que esto no implica mayor riesgo.

\section{Dra. Juliana Fassi [ Servicio de Endocrinología y Medicina Nuclear. Hospital Italiano de Buenos Aires.]}

Fassi J. Mayores requerimientos de levotiroxina en embarazadas con hipotiroidismo. Evid. actual. práct. ambul. 2004;7:165. Comentado de: Timing and magnitude of increases in levothyroxine requirements during pregnancy in women with hypothyroidism. Alexander $\mathrm{E} \mathrm{K}$, Marqusee $\mathrm{E}$, Lawrence $\mathrm{J}$ y col. $\mathrm{N}$ Engl J Med 2004,351:241-9.

\section{Referencias}

1.Surks MI, Ortiz E, Daniels GH, Sawin CT, et al. Subclinical Thyroid Disease. Scientific review and guidelines for diagnosis and management. JAMA 2004;291(2):228-238. 2.Amino N, Tada H, Hidaka Y. Autoinmune thyroid disease and pregnancy. J Endocrinol Invest 1996;(19):59-70. 3.Burrow G, Fisher DA, Larsen PR. Maternal and Fetal thyroid function. N Engl J Med 1994:331(16):1072-1078 